\title{
Measurement of directional lever response reaction time with the Commodore 64
}

\author{
RICHARD D. WRIGHT \\ Simon Fraser University, Burnaby, British Columbia, Canada \\ and \\ MICHAEL R. W. DAWSON \\ University of Alberta, Edmonton, Alberta, Canada
}

\begin{abstract}
Routines are described for timing directional lever responses with the Commodore 64 microcomputer. Millisecond reaction timing is carried out with on-board hardware clocks, and lever responses are detected by monitoring the position of a joystick interfaced to a controller port. In a demonstration program, a machine code subroutine is used to measure the reaction times of lever responses in a spatial relations task. In addition, modifications to the demonstration program are suggested to adapt it for use with other tasks.
\end{abstract}

Reaction time is one of the primary measures of human performance of interest to psychologists. Most reaction time tasks require subjects to press one or more buttons as quickly as possible after making some kind of decision. Related tasks have been carried out with a microphone and an accompanying voice onset time (VOT) apparatus. These tasks usually require subjects to make a vocal response into the microphone as quickly as possible after making a decision. A third method of obtaining reaction time responses involves the subject's moving a lever in one of several directions after making a decision. In this paper, we focus on the third method, and we describe routines for measuring reaction times and detecting lever movements with the Commodore 64 microcomputer. We also describe an example program in which lever responses are made in a four-choice reaction time task.

Before we discuss lever responses, it will be useful to consider the relative advantages and disadvantages of button and VOT responses. In a choice reaction time task, data collection is usually faster and more precise with button responses. In particular, buttons usually indicate the nature of the response, whereas VOTs simply stop a timer. Response type must then be entered as an additional step by either the subject or the experimenter on each trial. In addition, VOT responses tend to be more variable than button responses because of differences in the relative location of the first stop consonant (see Pringle \& Egeth,

This project was supported by a Natural Sciences and Engineering Research Council of Canada (NSERC) postdoctoral fellowship and a Simon Fraser University President's Research Grant awarded to R. W. and by NSERC Grant A2038 awarded to M. D. We are grateful to Lawrence Ward and Neil Watson for their comments and advice. Address correspondence to R. Wright, Department of Psychology, Simon Fraser University, Burnaby, BC, Canada V5A 1S6 (internet e-mail: richard_wright@sfu.ca).
1988 , p. 720 ). On the other hand, VOT responses are sometimes preferable because they are not affected by hemispheric laterality to the same extent that button responses are. It is well known that the left hemisphere of normal subjects is usually dominant (see, e.g., Annett, 1972; Bryden, 1982), and, as a result, subjects are often able to press a button faster with the right hand than with the left hand (Fisk \& Goodale, 1983). Laterality effects are traditionally controlled for whenever subject counterbalancing is not suitable by counterbalancing hand-button mappings. However, mapping switches can sometimes be difficult for subjects, and reaction times can be affected by interference from earlier mappings. VOT responses are also preferable to button responses if there are several response alternatives. Button responses are best suited for a two-choice task in which subjects use the fingers on the left hand to press one button and the fingers on the right hand to press another (see Blackman, 1972).

An alternative to button and VOT responses is the lever response. When a lever is used as part of a choice reaction time task, subjects move it in one of several directions to indicate their choices (see, e.g. , Eriksen \& St. James, 1986; Eriksen \& Yeh, 1985). Lever responses are superior to VOT responses in the same ways that button responses are, because voice onset factors do not affect the timing precision of lever responses and the experimenter or subject is not required to record the type of response manually after each trial. Lever responses are also superior to button responses in some ways. In particular, the same hand can be used for all lever responses in choice reaction time tasks, thus eliminating some concerns about hemispheric laterality. Furthermore, hand counterbalancing to completely control for laterality effects on lever responses can be carried out without requiring subjects to change their response mappings. That is, the lever is moved in the same directions to indicate the same responses, regardless of which hand moves the lever. More- 
over, subjects can move a lever in several different directions to make responses, and each direction could correspond to a different choice, whereas button responses are best suited for a two-choice task. Thus, lever responses are, in several ways, preferable to both button and VOT responses.

\section{Programming Reaction Time Lever Responses}

The Commodore 64 microcomputer is an inexpensive machine, but it has many features that make it an attractive choice as a laboratory computer (see, e.g., Horrman \& Allen, 1987; Kallman, 1986; Wright \& Dawson, 1988). For instance, the Commodore 64 has two 6526 complex interface adapters (CIAs) that control its input/output operations. Both chips have hardware clocks and data ports that are available for programming by the user. Furthermore, each CIA has two 16-bit 1.022-MHz timers that can be cascaded to measure durations with millisecond precision. These timers run independently of the 6510 CPU. In addition, CIA 1 is interfaced with two controller ports and can read data received through these ports from external devices such as mice and joysticks. Therefore, each CIA can be programmed as a millisecond timer that can be stopped with lever response input received through a controller port.

The two 16-bit timers (Timer A and Timer B) of CIA 2 are available to the user except when the operating system uses them for serial communications. These timers can be cascaded so that Timer B decrements its current value every time that Timer A counts down to zero. Thus, if Timer $A$ is programmed to count down to zero once every millisecond, Timer B is a millisecond counter. Six registers must be initialized in order to cascade Timer $A$ and Timer $\mathbf{B}$. The procedures involved in initializing these registers have been described in detail by Wright and Dawson (1988, pp. 42-43), and they are included in Listing 1 (see lines 1-14). In particular, Control Register B of CIA 2 (located at memory address 56591) must have bits 0 and 6 set to 1 . This initializes Timer A and Timer B as a single, cascaded timer. Timer $\mathrm{A}$ is programmed to count down to zero every millisecond by setting its low byte register (56580) to 252 and its high byte register (56581) to 3 . Timer B is initialized as a counter by setting its low byte (56582) and high byte (56583) registers to 255 . Millisecond timing can then be started by setting bit 0 of Control Register A (56590) to 1. Similarly, timing can be stopped by setting this bit to 0 (see lines 18 and 19 of Listing 1 ).

When timing has stopped, the reaction time can be determined by examining Timer B's low byte and high byte registers (see lines 380 and 390 of Listing 2). Wright (1986) described a similar procedure for programming the Commodore Amiga's 8520A CIAs for cascaded timing.

CIA 1 is interfaced to Controller Ports 1 and 2. As a result, CIA 1 can read the position of a joystick plugged into Controller Port 2 by reading Data Port A (56320). The first 4 bits of this register correspond to the joystick's
LISTING 1

A Machine Code Subroutine for Initializing CIA 2 as a Cascaded Millisecond Timer and for Polling Data Port $A$ for a Lever Movement Required to Stop Timing

\begin{tabular}{|c|c|c|c|c|c|c|c|}
\hline Line & $\begin{array}{l}1 \\
1\end{array}$ & $\begin{array}{l}\text { Address } \\
\text { Decrul Hex }\end{array}$ & 1 & $\begin{array}{l}\text { Machine } \\
\text { Code }\end{array}$ & $\begin{array}{l}1 \\
1\end{array}$ & $\begin{array}{c}\text { Assembly Code } \\
\text { Program }\end{array}$ & $\begin{array}{l}\text { Program } \\
\text { Comments }\end{array}$ \\
\hline 1 & 1 & $49152 C 000$ & I & A9 80 & 1 & LDAIM 128 & I Set up CIA \#2 for \\
\hline 2 & 1 & $49154 C 002$ & 1 & 8D 03 DD & 1 & STA 56579 & | Cascaded Timing \\
\hline 3 & 1 & $49157 \mathrm{CO05}$ & 1 & A9 $(x)$ & 1 & LDAIM & 1 \\
\hline 4 & $i$ & 491590007 & $i$ & $8 \mathrm{D} 0 \mathrm{DDD}$ & 1 & STA 56590 & 1 \\
\hline 5 & 1 & $49162 \mathrm{COOA}$ & I & 8D OF DD & 1 & STA 56591 & I \\
\hline 6 & 1 & $49165 \mathrm{COOD}$ & I & A9 FC & 1 & LDAIM 252 & I Set Timer A \\
\hline$?$ & 1 & $49167 \mathrm{COOF}$ & 1 & $8 D 04 D D$ & i & STA 56580 & Low \& High Bytes \\
\hline 8 & 1 & $49170 \mathrm{CO} 12$ & 1 & A9 03 & 1 & LDAIM 3 & i \\
\hline 9 & 1 & 491720014 & 1 & 8D 05 DD & 1 & STA 56581 & 1 \\
\hline 10 & 1 & 491750017 & $i$ & $\mathrm{~A} 9 \mathrm{FF}$ & i & LDAIM 255 & Set Timer B \\
\hline 11 & i & $49177 C 019$ & i & $8 \mathrm{D} 06 \mathrm{DD}$ & i & STA 56582 & Low \& High Bytes \\
\hline 12 & 1 & $49180 \mathrm{CO} 1 \mathrm{C}$ & 1 & 8D $07 \mathrm{DD}$ & 1 & STA $\quad 56583$ & । \\
\hline 13 & 1 & $49183 \mathrm{CO} / \mathrm{F}$ & 1 & A9 41 & 1 & LDAIM 65 & 1 \\
\hline 14 & 1 & $49185 \mathrm{CO21}$ & i & $8 \mathrm{D}$ OF DD & i & STA 56591 & i \\
\hline 15 & $i$ & $49188 \mathrm{CO24}$ & i & A901 & i & LDAIM i & Stan Timing \& \\
\hline 16 & I & $49190 \mathrm{C026}$ & I & 8D OE DD & 1 & STA $\quad 56590$ & J Jump to Line 26 \\
\hline 17 & I & 491930029 & I & $2041 \mathrm{CO}$ & 1 & JSR 49217 & 1 \\
\hline 18 & 1 & $49196 \mathrm{CO2C}$ & i & A9 00 & 1 & LDAIM 0 & Stop Timing \\
\hline 19 & 1 & $49198 \mathrm{CO2E}$ & 1 & 8D OE DD & 1 & STA 56590 & 1 \\
\hline 20 & 1 & $49201 \mathrm{CO} 031$ & 1 & $A D O D D D$ & 1 & LDA $\quad 56589$ & 1 \\
\hline 21 & $i$ & $49204 \mathrm{CO34}$ & $i$ & $\mathrm{AD} 06 \mathrm{DD}$ & 1 & LDA $\quad 56582$ & I Store Timer B \\
\hline 22 & 1 & 492070037 & 1 & $8 D 3503$ & 1 & STA & I Low Byte in 821 \\
\hline 23 & $i$ & $49210 \mathrm{COBA}$ & 1 & $A D 07 \mathrm{DD}$ & 1 & LDA 56583 & Store Timer B \\
\hline 24 & 1 & 49213 CO3D & I & $8 D 3603$ & 1 & STA & 3 High Byte in 822 \\
\hline 25 & $i$ & 492160040 & i & 60 & i & RTS & i not \\
\hline 26 & 1 & $49217 \mathrm{CO} 41$ & 1 & $A D 00 D C$ & 1 & LDA $\quad 56320$ & Poll Data Port A \\
\hline 27 & $i$ & $49220 \mathrm{CO44}$ & $i$ & $\mathrm{C} 97 \mathrm{~F}$ & i & CMPIM 127 & $(56320)$ for a \\
\hline 28 & 1 & $49222 \mathrm{CO} 46$ & i & FO F9 & 1 & $\mathrm{BEQ} \quad 249$ & I Lever Response \\
\hline 29 & 1 & $49224 \mathrm{CO} 48$ & 1 & $\mathrm{C} 97 \mathrm{~B}$ & 1 & CMPIM 123 & 1 \\
\hline 30 & i & $49226 \mathrm{CO} 4 \mathrm{~A}$ & i & Fo OF & i & $\mathrm{BEQ} \quad 15$ & i \\
\hline 31 & 1 & $49228 \mathrm{CO} 4 \mathrm{C}$ & i & C 977 & i & CMPIM 119 & i \\
\hline 32 & 1 & $49230 \mathrm{CO} 4 \mathrm{E}$ & 1 & F0 11 & 1 & BEQ & 1 \\
\hline 33 & $i$ & $49232 \cos 0$ & i & C9 7E & i & CMPIM 126 & 1 \\
\hline 34 & 1 & 49234 C052 & I & Fo 13 & 1 & BEQ & 1 \\
\hline 35 & 1 & $49236 \quad 054$ & 1 & C97D & 1 & CMPLM 125 & 1 \\
\hline 36 & 1 & $49238 \mathrm{cos} 6$ & 1 & F0 15 & 1 & $\mathrm{BEQ} \quad 21$ & i \\
\hline 37 & 1 & $49240 \mathrm{C058}$ & 1 & $4 \mathrm{C} 41 \mathrm{CO}$ & 1 & JMP $\quad 49217$ & i \\
\hline 38 & $i$ & 49243 CO5B & i & A9 01 & $i$ & LDAIM 1 & I Store Response \\
\hline 39 & 1 & $49245 \mathrm{COSD}$ & I & 8D 3403 & 1 & STA & 1 Type in Memory \\
\hline 40 & $i$ & $49248 C 050$ & i & 60 & $i$ & RTS & at Location 820 \\
\hline 41 & 1 & $49249 C 051$ & I & A902 & 1 & LDAIM & i \\
\hline 42 & 1 & $49251 \quad 0063$ & 1 & $8 D 3403$ & 1 & STA $\quad 820$ & I \\
\hline 43 & $i$ & $49254 \mathrm{C} 066$ & i & 60 & $i$ & RTS & i \\
\hline 44 & $i$ & $49255 \mathrm{C} 067$ & 1 & A9 03 & 1 & LDAMM & I (this routine \\
\hline 45 & $i$ & 492570069 & i & 8D 3403 & $\mathrm{i}$ & STA 820 & returns to \\
\hline 46 & 1 & $49260 \mathrm{CO} 6 \mathrm{C}$ & I & 60 & i & RTS & I Line 18 when \\
\hline 47 & i & 49261 CO6D & I & A9 04 & 1 & LDAIM & I finished) \\
\hline 48 & $i$ & $49263 \mathrm{CO} 6 \mathrm{~F}$ & i & 8D 3403 & $i$ & STA 820 & : \\
\hline 49 & $i$ & $49266 \mathrm{C} 072$ & i & 60 & $i$ & RTS & $i$ \\
\hline
\end{tabular}

current position (up, down, left, right). Moreover, information provided by these bits can be combined to determine which of eight possible positions the joystick is inup, down, left, right, up left, down left, up right, or down right. Thus, a joystick serves quite well as a response lever mechanism for the Commodore 64 .

Listing 1 is a machine code routine for initializing Timer A and Timer B of CIA 2 for cascaded millisecond timing, and for polling Data Port A for a lever movement required to stop timing. The routine is stored in memory between addresses 49152 and 49266 because this area is protected from being overwritten. Lines 1-16 of Listing 1 initialize the CIA 2 registers for millisecond timing and start the timer. Line 17 causes a jump to a polling subroutine beginning at address 49217 . The polling subroutine (lines 38-49) repeatedly tests to determine whether the lever has been moved. When a movement occurs, the subroutine then tests to determine the direction of the movement. It assigns the response labels $1,2,3$, and 4 to the movements left, right, up, and down, respectively. The response label corresponding to the movement that occurred is then stored at address $\mathbf{8 2 0}$ for future reference. After this has been carried out, program control 
returns from the subroutine to lines $18-25$. Timing is stopped at this point, and the values of the Timer B low byte and high byte registers are stored at addresses 821 and 822 , respectively. Then, program control is passed back to the BASIC program.

This machine code routine allows the millisecond reaction timer to be terminated with a high degree of precision by any of four possible lever movements. To elaborate, millisecond timing is carried out by CIA 2's hardware clocks and is therefore independent of the CPU's operations. This allows the CPU to be completely dedicated to polling Data Port A for a response. When a response occurs, its label is immediately stored in memory and timing is stopped within $1 / 20$ of a millisecond of the time that the lever response was made. This routine is more elaborate than those described by others (e.g., Hormann \& Allen, 1987), because it monitors four different directions of lever movement and can be modified to monitor eight directions.

\section{A Spatial Relations Program Incorporating the Reaction Time Lever Response Routine}

Lever responses are particularly appropriate for choice reaction time tasks designed to study hemispheric laterality effects. As mentioned previously, counterbalancing of handedness does not affect lever-response mappings but does affect button-response mappings. This makes the lever response quite suitable for research on the effects of laterality on spatial analysis (Kosslyn, 1987; Kosslyn et al., 1989). Kosslyn and his colleagues found that reaction times for judgments about the spatial relations between two objects depended on the nature of the judgment being made, and also on the visual hemifield in which the objects were presented. Observers made faster categorical judgments (e.g., Is Object A located on or off Object B?) when the objects were presented in the right hemifield rather than the left hemifield. In contrast, observers made faster coordinate (distance) judgments (e.g., How close is Object A to Object B?) when the objects were presented in the left visual hemifield rather than the right visual hemifield. A lever response is particularly appropriate for judgments of the distance between objects because several different proximity responses can be made with one hand.

The BASIC program in Listing 2 implements a simplified version of a distance judgment task (see, e.g., Hellige \& Michimata, 1989; Kosslyn et al., 1989). Before participating in this experiment, subjects are told that a target will be presented either above or below a line in the left or right visual hemifield. Their task is to judge the proximity of the target to the line and respond by moving the lever in one of four directions. That is, a move left corresponds to "very near," a move up corresponds to "near," a move right corresponds to "far," and a move down corresponds to "very far." After a target has been presented and a response has been made, reaction time (in milliseconds) and response accuracy are printed at the top of the display screen for $2 \mathrm{sec}$ before the next

\section{LISTING 2}

A BASIC Program for Loading and Calling the Machine Code Subroutine in Listing 1 and for Carrying out a Spatial Relations Demonstration Experiment

\begin{tabular}{|c|c|}
\hline 10 & 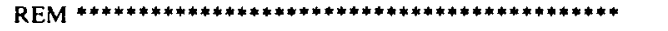 \\
\hline 20 & REM *** LOAD MACHINE CODE INTO MEMORY *** \\
\hline 30 & REM $* * * * * * * * * * * * * * * * * * * * * * * * * * * * * * * * * * * * * * * * * * * *$ \\
\hline 40 & POKE 646, 7: POKE 53280, 0: POKE 53281, 0: PRINT " $\underline{\text { " }}$ \\
\hline 50 & FOR $1=49152$ TO 49266: READ X: POKE $l, X:$ NEXT \\
\hline 60 & DATA $169,128,141,3,221,169,0,141,14,221,141,15$ \\
\hline 70 & DATA $221,169,252,141,4,221,169,3,141,5,221,169$ \\
\hline 80 & DATA $255,141,6,221,141,7,221,169,65,141,15,221$ \\
\hline 90 & DATA $169,1,141,14,221,32,65,192,169,0,141,14$ \\
\hline 100 & DATA $221,173,13,221,173,6,221,141,53,3,173,7$ \\
\hline 110 & DATA $221,141,54,3,96,173,0,220,201,127,240,249$ \\
\hline 120 & DATA $201,123,240,15,201,119,240,17,201,126,240$ \\
\hline 130 & DATA $19,201,125,240,21,76,65,192,169,1,141,52$ \\
\hline 140 & DATA $3,96,169,2,141,52,3,96,169,3,141,52,3,96$ \\
\hline 150 & DATA $169,4,141,52,3,96,1429,1857,1337,1069$ \\
\hline 160 & DATA $1589,1829,1617,1709,1097,1737,1189,1217$ \\
\hline 170 & DATA $1309,1949,1457,1977$ \\
\hline 180 & REM POKE 49226, 234: POKE 49227, 234 \\
\hline 190 & REM POKE 49230, 234: POKE 49231, 234 \\
\hline 200 & REM POKE 49234, 234: POKE 49235, 234 \\
\hline 210 & REM POKE 49238, 234: POKE 49239, 234 \\
\hline 220 & REM $* * * * * * * * * * * * * * * * * * * * * * * * * * * * * * * * * * * * * * * * * * * *$ \\
\hline 230 & REM **** DISPLAY FIXATION CROSS \& LINES **** \\
\hline 240 & $\mathrm{REM}^{* * * * * * * * * * * * * * * * * * * * * * * * * * * * * * * * * * * * * * * * * * * * *}$ \\
\hline 250 & POKE 1523, 91: FOR I = 1506 TO 1512: POKE I, 224 \\
\hline 260 & POKE I + 28, 224: NEXT I: PRINT "PRESS KEY TO BEGIN" \\
\hline 270 & GET A\$: IF AS = "" THEN 270 \\
\hline 280 & $\mathrm{TA}=1060$ \\
\hline 290 & REM $* * * * * * * * * * * * * * * * * * * * * * * * * * * * * * * * * * * * * * * * * * * *$ \\
\hline 300 & REM **** DISPLAY TARGET \& START TIMER ***** \\
\hline 310 & REM $* * * * * * * * * * * * * * * * * * * * * * * * * * * * * * * * * * * * * * * * * * * * *$ \\
\hline 320 & FOR $C=1$ TO 16: POKE TA. 32: READ TA: POKE TA, 81 \\
\hline 330 & SYS 49152 \\
\hline 340 & PRINT "S": PRINT" \\
\hline 350 & $\mathrm{REM}^{* * * * * * * * * * * * * * * * * * * * * * * * * * * * * * * * * * * * * * * * * * * *}$ \\
\hline 360 & REM * DETERMINE RESPONSE \& REACTION TIME * \\
\hline 370 & REM $* * * * * * * * * * * * * * * * * * * * * * * * * * * * * * * * * * * * * * * * * * * *$ \\
\hline 380 & $\mathrm{LO}=255-\operatorname{PEEK}(821): \mathrm{HI}=255-\operatorname{PEEK}(822)$ \\
\hline 390 & $\mathrm{RT}=\mathrm{HI} * 256+\mathrm{LO}: \mathrm{Z}=\operatorname{PEEK}(820)$ \\
\hline 400 & IF $\mathrm{Z}=1$ THEN RS = "LEFT " \\
\hline 410 & IF $\mathrm{Z}=2$ THEN RS $=$ "RIGHT " \\
\hline 420 & IF $\mathrm{Z}=3$ THEN RS = "UP \\
\hline 430 & IF $\mathrm{Z}=4$ THEN $\mathrm{RS}=$ "DOWN " \\
\hline 440 & PRINT "S": PRINT" \\
\hline 450 & FOR I $=1$ TO 200: NEXT I: NEXT C: END \\
\hline
\end{tabular}

trial is initiated. The program provides an example of how the lever response reaction time subroutine in Listing 1 can be implemented in an experiment.

The example program works in the following way: First, the machine code subroutine is poked into memory at the beginning of the program for the benefit of those without access to an assembler (lines 10-170 of Listing 2). Following this, the screen is cleared and a fixation cross and two reference lines are displayed on it with one line in each visual hemifield (lines 220-280). At this point, a trial begins with the presentation of a target at one of four positions above or below one of the reference lines. The machine code subroutine is then called with the command SYS 49152 . When a lever response is made, the subroutine returns control to the BASIC program and the target is erased. Then the addresses for temporary storage of the response label and the Timer $B$ low and high bytes $(820,821$, and 822$)$ are examined to determine the 
reaction time and the direction that the lever was moved (lines 340-450).

Lever responses are readily implemented on the Commodore 64 and are easy to modify. For example, the BASIC program in Listing 2 can be modified to change the number of possible lever movements from four to three, two, or one. To deactivate the "left" response, the REM statement should be removed from line 180 . Similarly, to deactivate the "right," "up," and "down" responses, the REM statements should be removed from lines 190,200 , and 210 , respectively. Thus the number of different lever movements that will terminate reaction timing can be varied from one to four. This provides the programmer with a great deal of flexibility when designing experiments.

\section{REFERENCES}

ANNETT, M. (1972). The distribution of manual asymmetry. British Jowrnal of Psychology, 63, 343-358.

Blackman, A. R. (1972). Influence of stimulus and response probability on decision and movement latency in a discrete choice reaction cask. Joumal of Experimental Psychology, 92, 128-133.

Bryden, M. P. (1982). Laterality: Functional asymmetry in the intact brain. New York: Academic Press.

ERIKSEN, C. W., \& ST. JAmes, J. D. (1986). Visual attention within and around the field of focal attention: A zoom lens model. Perception \& Psychophysics, 40, 225-240.

ERJKSEN, C. W., \& YEH, Y. (1985), Allocation of attention in the visual field. Journal of Experimental Psychology: Human Perception \& Per. formance, 11, 583-597.
FisK, J. D., \&oOdale, M. A. (1983). The organization of eye and limb movements during unrestricted reaching to targets in contraiateral and ipsilateral visual space. Experimental Brain Research, 60, 159-178.

Hellige, J. B., \& Michimata, C. (1989). Categorization versus distance: Hemispheric differences for processing spatial information. Memory \& Cognition, 17, 770-776.

HormanN, C. A., \& ALLEN, J. D. (1987). An accurate millisecond timer for the Commodore 64 or 128. Behavior Research Methods, Instruments, \& Computers, 19, 36-41.

Kallman, H. J. (1986). A Commodore 64-based experimental psychology laboratory. Behavior Research Methods, Instruments, \& Computers, 18, 222-227.

Kosslyn, S. M. (1987). Seeing and imagining in the cerebral hemispheres: A computational approach. Psychological Review, 94, 148-175.

Kosslyn, S. M., Koenig, O., Barrett, A., Cave, C. B., Tang, J., \& Gabrieli, J. D. E. (1989). Evidence for two types of spatial representations: Specialization for categorical and coordinate relations. Journal of Experimental Psychology: Human Perception \& Performance, 15, 723-735.

Pringle, R., Egeth, H. E. (1988). Mental curve tracing with elementary stimuli. Journal of Experimental Psychology: Human Perception \& Performance, 14, 716-728.

WrIGHT, R. D. (1986). Amiga 1000 hardware timing and reaction-time key interfacing. Behavior Research Methods, Instruments, \& Computers, 18, 463-465.

WRIGHT, R. D., \& DAwson, M. R. W. (1988). Using hardware interrupts for timing visual displays and reaction-time key interfacing on the Commodore 64. Behavior Research Methods, Instruments, \& Computers, 20, 41-48.

(Manuscript received February 10, 1992; revision accepted for publication May 26, 1992.) 